\title{
The ApPlication Of Resilient ARChitecture ConcePT In The OCEANARIUM Design In PARANGTRITIS
}

\section{Penerapan Resilient ARChitecture Dalam PERANCANGan OSEANARIUM Di PARANGTRITIS}

\author{
Bidari Putri $\mathbf{R}^{1^{*} \text {, Agung Kumoro } \mathrm{W}^{2} \text {, Hardiyati }}{ }^{3}$ \\ Program Studi Arsitektur, Fakultas Teknik, Universitas Sebelas Maret ${ }^{1}$ \\ *Email : bidari.putri@gmail.com* \\ Program Studi Arsitektur, Fakultas Teknik, Universitas Sebelas Maret ${ }^{2}$ \\ Program Studi Arsitektur, Fakultas Teknik, Universitas Sebelas Maret ${ }^{3}$
}

\begin{abstract}
Indonesia has a huge diversity of marine biota but there is degradation based on IUCN Red List. In this case, the preservation of marine biota is necessary. Besides that, Yogyakarta has a big potential to develop the maritime tourism especially in Parangtritis Beach. However, the location is susceptive with the external interferences like earthquake, windstorm, and tsunami. Therefore, it is necessary to build oceanarium which can protect the marine biota with three functions; recreation, education, and preservation. Furthermore, the design of oceanarium uses the resilient architecture approach that is adaptive towards the external interferences (earthquake, windstorm, and tsunami). The method which is used is descriptive qualitative with case study of resilient architecture literature, physical condition of site and government regulation. The application of resilient architecture is applied to five aspects of design; site (evacuation access, minimum height, and assembly point), form and mass (modification and circle application), building appereance (material that has durability), structural systems (construction system that withstands earthquake and tsunami). The analysis process produces an oceanarium design that accommodates marine biota and adaptive towards the external interferences (earthquake, windstorm, and tsunami).
\end{abstract}

Keywords: Preservation, Oceanarium, Resilient Architecture, Parangtritis.

\section{PENDAHULUAN}

Indonesia merupakan negara kepulauan yang sepertiga bagian atau $63 \%$ merupakan daerah perairan. Menurut Damayanti (2015) bentuk negara kepulauan ini seolah-olah membatasi interaksi antara masyarakat Indonesia dengan biota laut, sehingga kehidupan bawah laut kurang mendapatkan apresiasi.

Banyak keragaman biota laut yang hidup di Negara Indonesia baik di daratan maupun di perairan. Akan tetapi, potensi biota laut tersebut mengalami degradasi dimana organisasi IUCN menyatakan beberapa spesies biota laut Indonesia masuk dalam Red List of Threatened Species. Menurut Meikalista (2016) hal tersebut terjadi akibat aktivitas-aktivitas manusia yang membahayakan lingkungan.

Parangtritis sampai saat ini hanya memiliki sedikit wadah penangkaran khusus biota laut diantaranya; penangkaran penyu di Pantai Pelangi dan Pantai Trisik. Sehingga, dapat dikatakan bahwa masih sangat kurang adanya wadah pelestarian bagi biota laut. (Sunarto, Marfai, \& Mardiatno, 2010).

Ditambah lagi, Parangtritis memiliki potensi besar untuk pengembangan pariwisata bahari khususnya Pantai Parangtritis. Akan tetapi, sarana dan prasarana di Parangtritis hanya berupa pengolahan pantai saja sedangkan dunia bawah laut hanya dapat dinikmati dengan cara 
menyelam sehingga banyak masyarakat yang belum mengetahui potensi bawah laut dengan keanekaragaman biota laut yang ada di Indonesa (Ambarwulan \& Wulan, 2016). Disamping itu, daerah Parangtritis merupakan kawasan tumbukan lempeng antara Eurasia, Indo-Australia, dan Pasifik di dasar Samudera Hindia sehingga sangat rentan terhadap faktor eksternal seperti gempa bumi, badai angin, dan tsunami. (Mirza, 2015).

Berdasarkan pernyataan diatas dibutuhkan sebuah wadah yang memfasilitasi kegiatan mengenai potensi biota laut Indonesia yaitu oseanarium dengan desain bangunan yang memiliki daya tahan tinggi melalui pendekatan resilient architecture yang bersifat adaptif terhadap dampak gangguan eksternal.

Resilient architecture yang tertera didalam buku Unravelling Sustainability and Resilience in the Built Environment diartikan oleh Emilio Jose Garcia dan Brenda Vale sebagai desain bangunan yang beradaptasi dan melakukan penyesuaian terhadap perubahan kondisi dengan tetap mempertahankan fungsionalitas dalam menghadapi kerentanan terhadap faktor eksternal. Konsep dasar resilient architecture menurut Jose Garcia \& Vale (2017) mengidentifikasi penyebab dan sifat faktor eksternal yang akan dihadapi dan memahami penyebab terjadinya, penyebaran geografis, frekuensi kemunculan, dan mekanisme kerusakan fisik pada lokasi perancangan yaitu daerah Parangtritis yang rentan terhadap gempa bumi, badai angin, dan tsunami. Resilient architecture beradaptasi terhadap perubahan yang disebabkan oleh faktor eksternal dan menggunakan strategi desain yang meningkatkan daya tahan bangunan terhadap faktor eksternal.

Terdapat beberapa prinsip resilient architecture yang dijelaskan sebagai berikut berdasarkan teori dari Multirisk Assessment Of Disasters In Parangtritis Coastal Area (Sunarto, Marfai, \& Mardiatno, 2010), Vulnerability assessment and seismic risk reduction strategies of hospitals in Basilicata region (Masi, Santarsiero, \& Chiauzzi, 2012), Disaster Mitigation Approach Of Urban Green Structure Concept In Coastal Settlement (Mirza, 2015).

a. Sistem Jalur Evakuasi
Desain resilient architecture dipengaruhi oleh aspek aksesibilitas pada kawasan mengenai jalur evakuasi dan peletakan titik kumpul.

b. Ketinggian Minimum

Desain Bangunan resilient architecture diletakkan di standar ketinggian minimum terhadap area dengan dampak yang parah akibat faktor eksternal selain itu tinggi bangunan tidak melebihi empat kali lebar bangunan.

c. Bentuk Dasar Simetris

Desain bentuk denah resilient architecture direncanakan berbentuk dasar simetris seperti bentuk segi empat sama sisi atau lingkaran.

d. Material Berdaya Tahan

Material yang dipilih adalah material yang tahan terhadap tekanan air dan udara, daya apung, dampak reruntuhan, gelombang air, dan pergeseran tanah.

e. Sistem Struktur Tahan Gempa

Penggunaan sistem struktur yang dapat meredam getaran akibat Gempa Bumi.

Oseanarium merupakan sebuah tempat untuk memelihara biota-biota laut yang digunakan sebagai sarana pelestarian dan pengembangan kelautan yang dipamerkan sebagai sarana rekreasi (Widjaja, 2015). Oseanarium dalam membentuk suatu ekosistem terdapat persyaratan khusus yang diperhatikan pengadaan maupun perawatannya berdasarkan literature dari Akuarium Laut (Nursaiful, 2007), Time-Saver Standards for Building Types (De Chiara \& Crosbie, 2007), Organizing a Public Aquarium: Objectives; Design; Operation; and Missions (Karydis, 2011).

Sirkulasi dalam bangunan oseanarium dapat menyerupai pola yang mengalir sehingga menuntun pengunjung untuk melihat satu per satu tidak terhambat/terpusat di suatu tempat dan diberikan handrail sebagai batas antara pengunjung dengan kaca tangki berjarak $\pm 30 \mathrm{~cm}$ dengan tinggi $\pm 1 \mathrm{~m}$ dari lantai. (Nursaiful, 2007).

Bentuk akuarium disesuaikan dengan ukuran biota laut, kemudahan dalam perawatan, dan 
keindahan estetika. Ragam bentuk akuarium antara lain: bentuk bulat, bentuk memanjang ke atas, bentuk silinder, dan diorama. Sehingga, peletakan tangki mempertimbangkan ukuran; aksesibilitas; perawatan; pembersihan; dan pemipaan tangki.

\section{METODE}

Oseanarium yang dirancang menerapkan strategi desain dari teori Jose Garcia \& Vale (2017) untuk dapat beradaptasi terhadap gangguan faktor eksternal. Metode perancangan yang digunakan adalah deskriptif kualitatif dengan mentransformasikan konsep yang direncanakan menjadi ide desain yang dirancang.

Pemahaman teori resilient architecture diawali dengan fenomena-fenomena yang terjadi di Parangtritis dan dilanjutkan dengan tinjauan data. Sumber data primer pada penelitian ini berupa hasil kajian teori resilient architecture yang didapat melalui tinjauan pustaka, jurnal maupun artikel terkait. Pembahasan lebih terfokus pada penerapan strategi desain resilient architecture dibangunan Oseanarium.

Penerapan strategi desain resilient architecture diaplikasikan pada lima aspek perancangan, yaitu pengolahan tapak, pengolahan bentuk dan tata massa, pengolahan tampilan bangunan, dan sistem struktur.

\section{a. Pengolahan Tapak}

Strategi desain resilient architecture yang digunakan adalah integrasi antara tapak dengan massa bangunan dicapai melalui aspek aksesibilitas. Aspek aksesibilitas ditekankan pada sistem jalur evakuasi kawasan dan peletakan titik kumpul, selain itu pemilihan site terletak di ketinggian minimum.

b. Pengolahan Bentuk dan Tata Massa

Strategi desain resilient architecture yang digunakan denah direncanakan berbentuk dasar segi empat sama sisi atau lingkaran dengan tinggi bangunan tidak melebihi empat kali lebar bangunan.

c. Pengolahan Tampilan Bangunan

Strategi resilient architecture difokuskan pada pemilihan material dan penyusunan material sehingga dapat menunjang aspek estetika. Pada bagian luar bangunan dilakukan penyusunan material yang adaptif terhadap arah angin.

\section{d. Sistem Struktur}

Pengolahan struktur berhubungan dengan sistem struktur yang digunakan dapat meminimalisir dampak kerusakan akibat gempa bumi dengan meninjau peraturan yang berlaku di daerah Pantai Parangtritis. Strategi desain yang digunakan resilient architecture difokuskan pada pemilihan sistem struktur, material struktur, dan hubungan antara supper struktur; upper struktur; dan sub struktur.

\section{HASIL DAN PEMBAHASAN}

Desain bangunan oseanarium menerapkan teori resilient architecture dimana strategi desain yang dipilih dilakukan dengan memperhatikan tiga faktor eksternal, yaitu gempa bumi, badai angin, dan tsunami.

Penerapan pendekatan resilient architecture pada perancangan Oseanarium di Parangtritis menghasilkan sebuah oseanarium yang dapat mewadahi potensi biota laut dengan bangunan yang bersifat adaptif terhadap perubahan gangguan eksternal yang dominan (gempa bumi, badai angin, dan tsunami).

Hasil tersebut dapat dicapai melalui lima aspek perancangan yaitu sebagai berikut: pengolahan tapak, pengolahan bentuk dan tata massa, pengolahan tampilan luar bangunan, dan pengolahan sistem struktur.

\section{a. Pengolahan Tapak}

\section{Pemilihan Site}

Persyaratan dalam pemilihan site, diantaranya: (1) Memiliki kemudahan akses pencapaian. Kemudahan akses bepengaruh pada proses jalur evakuasi saat terjadi gangguan faktor eksternal dan proses pemindahan biota; (2) Berada pada batas aman ketinggian minimum; (3) Berada di lokasi dekat dengan laut untuk kemudahan pengadaan air laut.

Berdasarkan kriteria tersebut, maka diperoleh site yang bersesuaian pada wilayah Parangtritis. Site seluas 7 hektar yang dilewati oleh Jalan Parangtritis selebar 12 meter. Site berbatasan dengan Pantai Parangtritis serta ditempatkan di ketinggian minimum teraman dari ancaman tsunami di Parangtritis (lihat gambar 1). 


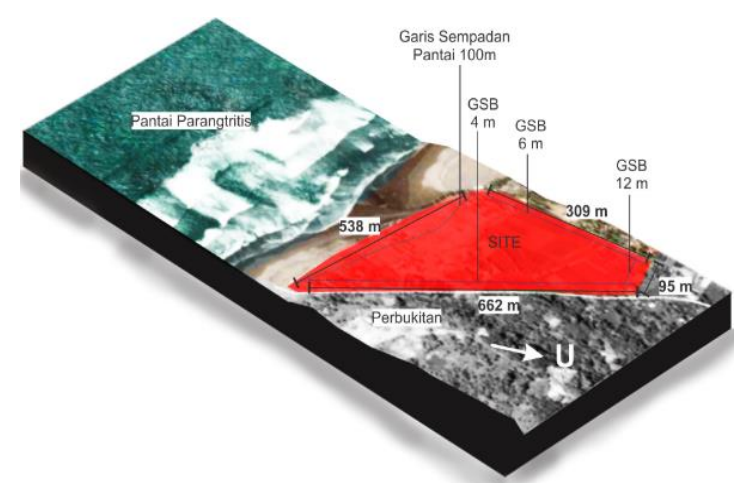

Gambar 1. Tapak eksisting terpilih

\section{Pencapaian Tapak}

Analisis pencapaian tapak memiliki tujuan untuk menentukan titik yang paling berpotensi mendukung kelancaran sirkulasi bangunan oseanarium khususnya sirkulasi jalur evakuasi, sehingga mempermudah akses pengunjung dan pengguna bangunan dalam evakuasi.

Faktor eksternal dominan pada pengolahan pencapaian tapak adalah tsunami sehingga penerapan resilient architecture ini didasarkan pada respon pencapaian terhadap lingkungan sekitar, mudah dikenali publik, dan kelancaran sirkulasi jalur evakuasi (lihat gambar 2).

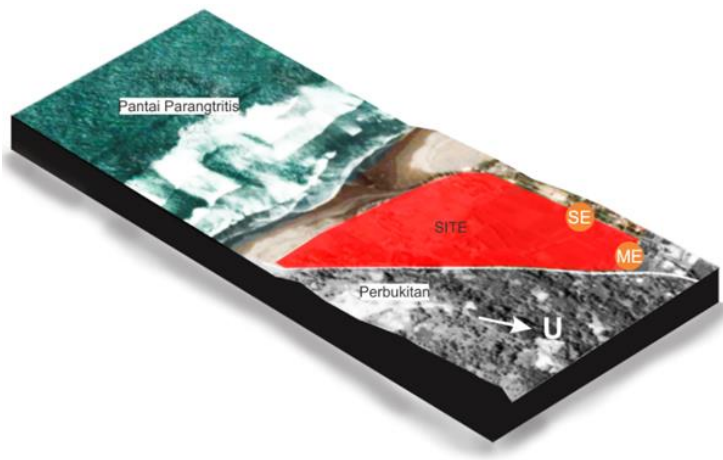

Gambar 2 Titik pencapaian menuju tapak

Berdasarkan gambar 2 akses utama menuju tapak berada di Jalan Parangtritis disimbolkan dengan huruf ME. Side entrance yang berfungsi sebagai jalur keluar masuk pengelola dan kendaraan angkut berat berada di sisi timur site agar tidak menimbulkan crossing dengan akses pengunjung.

Jalur evakuasi mengarah ke arah utara tapak yaitu menuju ke Jalan Parangtritis karena sisi utara tapak merupakan dataran yang lebih tinggi dan merupakan batas aman terhadap tsunami dengan ketinggian 6 meter.

\section{View pada Tapak}

Analisis view pada tapak eksisting bertujuan untuk mengetahui potensi view yang terdapat pada eksisting. Analisis view ini berkaitan erat dengan aspek keamanan lingkungan maupun bangunan dan aspek estetika karena view yang baik dapat memperlihatkan estetika dengan memperhatikan keamanan terhadap gangguan faktor eksternal.

Faktor eksternal dominan pada pengolahan view tapak adalah gempa bumi dan tsunami sehingga penerapan strategi desain pendekatan resilient architecture didasarkan pada respon arah orientasi bangunan terhadap arah datang gelombang dan arah jalur evakuasi yang dapat dilihat pada ilustrasi gambar 3 .

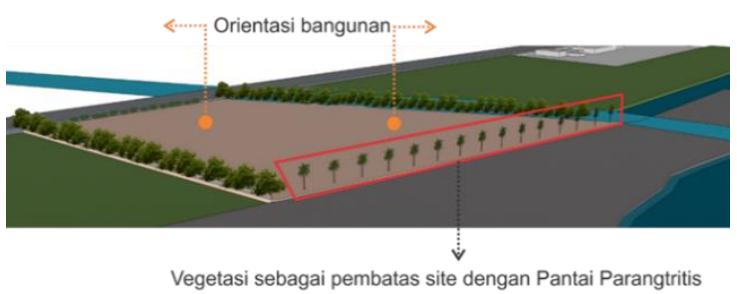

Gambar 3 Arah orientasi bangunan

Berdasarkan ilustrasi gambar 3 orientasi arah bangunan menghadap ke dua arah yaitu Jalan Parangtritis dan menghadap Pantai Parangtritis. Aspek keamanan dilihat dari orientasi yang mengarah ke Jalan Parangtritis dimaksudkan agar pengguna bangunan dapat mengenali arah jalur evakuasi kawasan sedangkan orientasi arah ke Pantai Parangtritis untuk mengetahui arah datangnya ombak. Batas antara site dengan Pantai Parangtritis berupa vegetasi yang dapat menahan ombak seperti bakau dan waru laut. Aspek estetika dapat dilihat pada orientasi yang mengarah ke Jalan Parangtritis dijadikan fasad utama yang representatif sebagai identitas dari kawasan bangunan oseanarium yang menarik perhatian pengunjung.

\section{Pengamanan Persitiwa Alam}

Pengolahan tapak pada pengamanan peristiwa alam berhubungan dengan penataan lansekap. Penataan lansekap sangat diperlukan untuk memperhitungkan peran tata lansekap dalam menciptakan kondisi yang diinginkan didalam eksisting khususnya dalam menentukan jalur evakuasi.

Faktor eksternal dominan pada pengamanan peristiwa alam adalah gempa bumi dan tsunami sehingga penerapan strategi desain resilient 
architecture didasarkan pada pembagian zona yang berdasarkan tingkat kerawanan bencana, komposisi bangunan diletakkan lebih tinggi atau sama dengan standar ketinggian minimum, penempatan titik kumpul, penataan jalur hijau dan jalur evakuasi yang dapat dilihat pada ilustrasi gambar 4 .

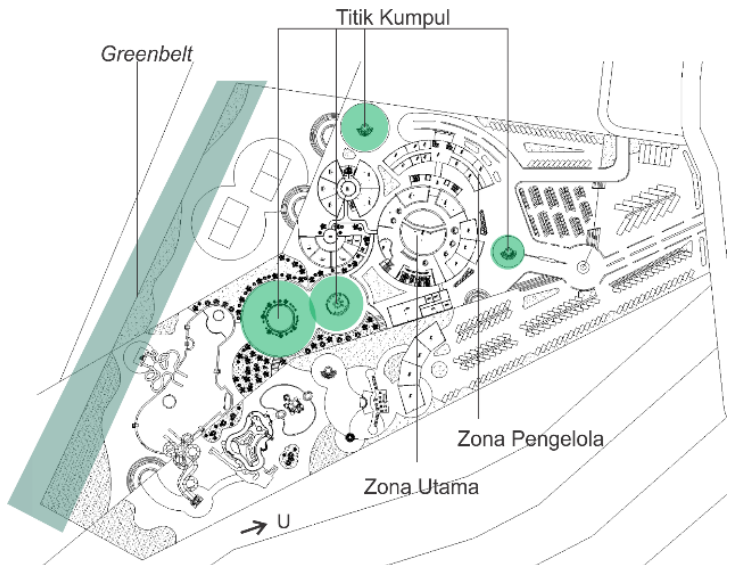

Gambar 4 Peletakan titik kumpul pada lansekap

Berdasarkan gambar 4 zona kegiatan yang memiliki tingkat aktivitas tinggi diletakkan pada kontur tanah yang lebih tinggi seperti zona utama dan zona pengelola. Arah jalur evakuasi mengarah ke lokasi dengan dataran yang lebih tinggi yaitu mengarah ke bagian utara site, hal ini berpengaruh dalam menentukan peletakan titik kumpul pada standar ketinggian minimum sehingga diletakkan pada empat titik seperti pada gambar 4.

Titik kumpul pada kawasan berbentuk taman sebagai penghubung antar massa bangunan sehingga pemilihan vegetasi pada taman berdasarkan kebutuhan dalam mengatasi arus ombak; potensi angin; dan kebutuhan estetika lansekap, seperti pemilihan vegetasi waru dan bakau pada jalur hijau (greenbelt) di bagian selatan site yang berfungsi memperlambat laju arus ombak dan terpaan air.

\section{b. Pengolahan Bentuk dan Tata Massa}

Analisis bentuk dan tata massa digunakan untuk menentukan bentuk dasar massa bangunan dan komposisi tata massa antar bangunan yang adaptif terhadap faktor eksternal.

Faktor eksternal dominan pada pengolahan bentuk dan tata massa adalah gempa bumi dan badai angin sehingga penerapan strategi desain didasarkan pada konfigurasi penataan massa bangunan, bentuk dasar denah yang rigid, dan bentuk gubahan massa simetris yang dapat dilihat pada gambar 5 .
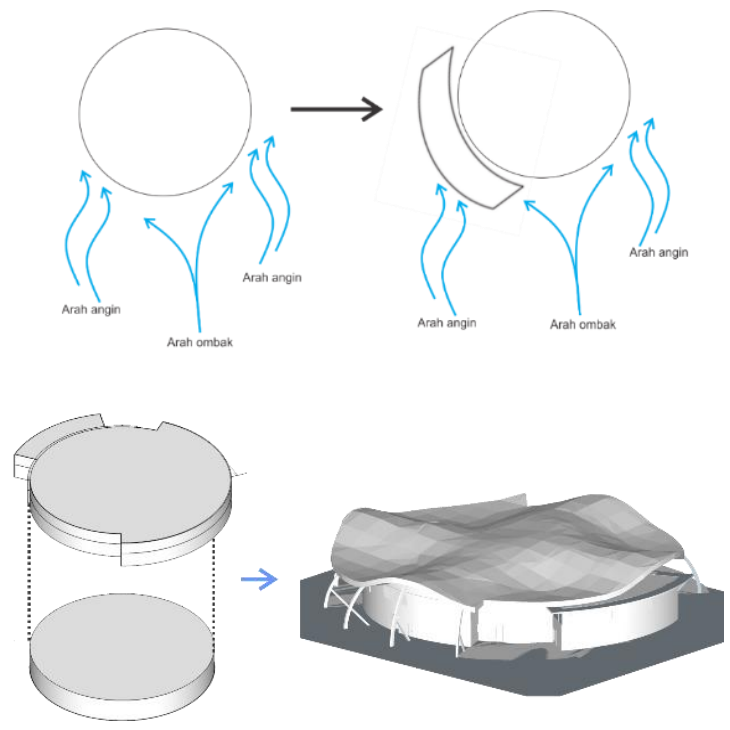

Gambar 5 Pengolahan bentuk bangunan oseanarium

Keputusan desain berdasarkan prinsip resilient architecture adalah bentuk dasar yang diambil adalah bentuk dasar lingkaran karena bentuk lingkaran merupakan bentuk yang simetris, rigid, dan adaptif terhadap tekanan angin.

Hasil bentuk massa adalah modifikasi dari bentuk lingkaran dengan adanya penambahan dan pengurangan dari bentuk dasar lingkaran yang disesuaikan dengan arah hembus angin, sehingga hembus angin yang kencang dapat terpecah dan tidak terpusat di satu titik.

Bentuk dasar atap pada bangunan oseanarium diadopsi dari bentuk tampilan gelombang yang dapat menimbulkan kesan dinamis dan bersifat massif sehingga gubahan massa tetap simetris.

Perancangan komposisi bangunan terdiri dari beberapa massa bangunan yang terpisah dan menyebar agar dapat memecah angin terutama dari arah pantai dan dibelokkan secara merata sehingga segala area dapat memperoleh angin sejuk.

\section{c. Pengolahan Tampilan Bangunan}

Analisis tampilan fisik bangunan digunakan untuk pemilihan material, mempertimbangkan bukaan, dan penyusunan material pada sisi luar bangunan serta memenuhi kriteria resilient architecture yang ingin disampaikan. 
Faktor eksternal dominan pada pengolahan tampilan bangunan adalah badai angin sehingga penerapan strategi desain resilient architecture didasarkan pada durabilitas material dinding luar, penyusunan material, dan arah hembus angin.

Penggunaan material yang tahan terhadap angin dan arus seperti beton dan batu alam sangat diperhitungkan karena material beton dan batu alam memiliki durabilitas yang tinggi.

Penggunaan material kaca pada dinding tidak massif dapat memenuhi nilai keringanan pada tampilan fisik. Kaca juga memiliki kelemahan yaitu adanya kemungkinan munculnya gaya getaran akibat bertabrakan dengan angin yang dapat mengakibatkan terjadinya retakan serta mudah menyerap panas ke dalam bangunan.

Berdasarkan pernyataan tersebut material kaca yang dipilih menggunakan kaca yang memiliki ketebalan $12 \mathrm{~mm}$ dengan finishing laminated glass dan penyusunan rangka kaca yang adaptif terhadap arah angin sehingga mampu menahan beban angin dan mengurangi penyerapan panas ke dalam bangunan. Material rangka kaca terbuat dari rangka baja yang memiliki nilai rigiditas tinggi. Ilustrasi rangka kaca dapat dapat dilihat pada gambar 6 .

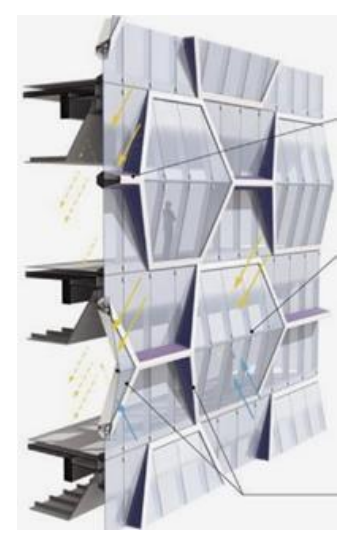

Gambar 6 Rangka kaca yang adaptif terhadap tekanan angin

Penggunaan kerangka baja dengan bentuk dasar heksagon dan permukaan yang cenderung tidak rata dimaksudkan agar dapat menahan beban tekanan angin dan dapat mengatur pencahayaan yang masuk ke dalam bangunan.

\section{d. Sistem Struktur}

Analisis sistem struktur pada massa bangunan bertujuan untuk menentukan sistem struktur utama yang digunakan dan diterapkan sesuai dengan karakteristik resilient architecture yang terbagi menjadi tiga poin yaitu upper struktur; supper struktur; dan sub struktur.

Faktor eksternal yang berperan penting dalam menentukan penggunaan resilient architecture adalah gempa bumi dan tsunami. Sehingga, keriteria penggunaan sistem struktur didasarkan pada peraturan standar yang berlaku di daerah Parangtritis, pemilihan material utama struktur yang ringan, sistem struktur yang monolit, dan penggunaan peredam mekanis pada landasan bangunan sebagai upaya antisipasi terhadap gempa bumi.

Peraturan-peraturan pemerintah yang berkaitan dengan perencanaan struktur gedung di daerah Parangtritis adalah: SNI-1727:2013 (Beban Minimum Perancangan Bangunan Gedung dan Struktur Lain); SNI-1726:2012 (Tata Cara Perencanaan Ketahanan Gempa untuk Struktur Gedung dan Non-Gedung); dan SNI-2847:2013 (Persyaratan Beton Struktural untuk Bangunan Gedung).

Peraturan-peraturan tersebut dijadikan dasar dalam menentukan sistem struktur dan material struktur dalam bangunan oseanarium, sehingga sketsa ide desain sistem struktur pada bangunan oseanarium dapat dilihat pada gambar 7 .

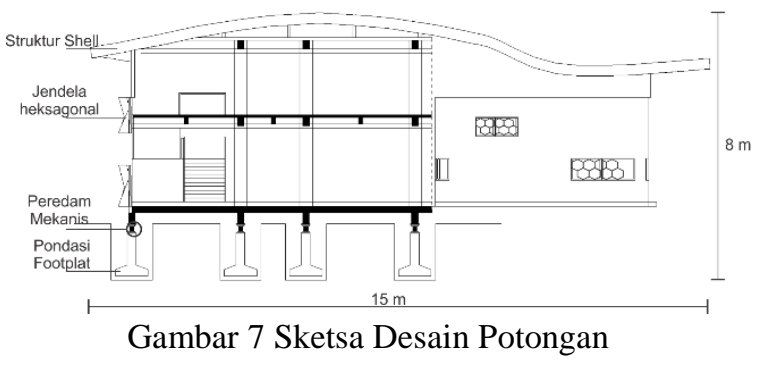

Berdasarkan gambar 7 sistem struktur yang digunakan pada bangunan oseanarium adalah:

\section{Upper struktur}

Upper struktur merupakan struktur atap atau bagian kepala dari sebuah bangunan. Upper struktur yang digunakan adalah shell structure merupakan struktural berdimensi tiga kaku dan tipis serta mempunyai permukaan lengkung.

Shell structure dipilih karena material utama yang digunakan adalah beton dengan tulangan baja yang merupakan struktur monolit dan sistem pembebanan mengalir ke titik tertentu 
dan tidak menyebar ke berbagai arah yang dapat dilihat pada gambar 8 .

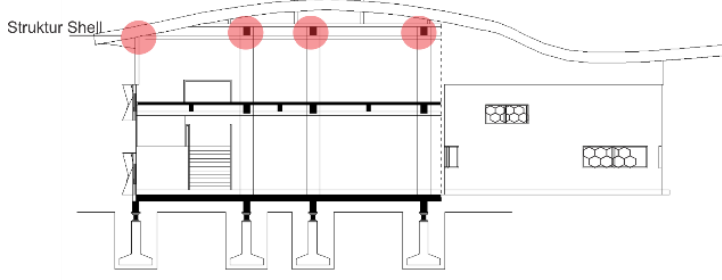

Gambar 8 Sketsa Pembebanan struktur atap

Berdasarkan ilustrasi gambar 8 terdapat empat titik pembebanan utama sehingga beban dari atap akan disalurkan ke struktur dibawahnya yang berupa tiang penyangga utama.

\section{Supper struktur}

Supper struktur meliputi dinding, kolom, dan balok. Dinding pada bangunan oseanarium menggunakan sistem non bearing wall. Non bearing wall adalah jenis struktur dinding yang tidak memikul beban atap dan hanya digunakan sebagai penutup bangunan atau pembatas ruang. Dinding non bearing wall juga berfungsi sebagai elemen pengaku pada bangunan secara keseluruhan.

Material dinding menggunakan bahan beton ringan yang memiliki sifat kuat, tahan air dan api. Pemilihan beton ringan sebagai material dinding dapat memperingan beban struktur dari sebuah konstruksi bangunan sehingga dapat meminimalisir sistem pembebanan.

\section{Sub struktur}

Sub struktur meliputi pondasi yang berfungsi sebagai penerima beban akhir suatu bangunan. Sistem sub struktur bangunan ini menggunakan sistem pondasi tiang pancang, sistem pondasi footplat, dan sistem peredam mekanis.

Pondasi tiang pancang adalah pondasi yang digunakan untuk bangunan berlantai banyak atau berbentang lebar. Bentang ruang yang ditopang oleh pondasi ini tidak terbatas dan berbanding lurus dengan kemampuan menahan bebannya. Pondasi tiang pancang digunakan pada tanah yang cukup keras. Pondasi foot plat digunakan pada tanah tidak keras. Pondasi footplat sesuai untuk bangunan dengan tinggi 24 lantai yang dapat dilihat pada gambar 9 .

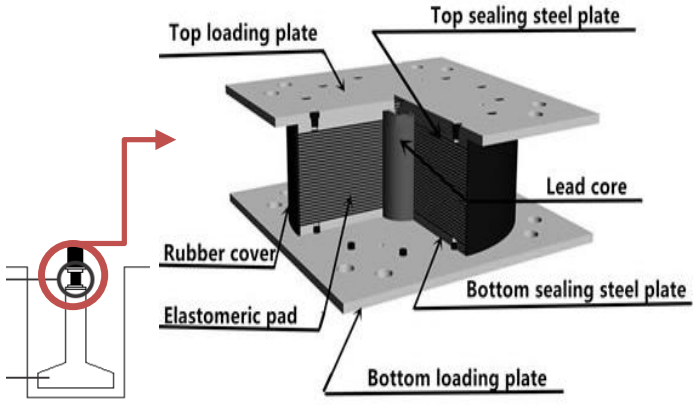

Gambar 9 Sketsa Sistem Pondasi Footplat

Penggunaan peredam mekanis yaitu berupa peredam yang terdiri dari dari lempengan baja dan karet dipasang pada landasan bangunan, kolom-kolom serta landasan balok sebagai bantalan. Peredam mekanis berfungsi untuk mengurangi getaran yang terjadi akibat gempa. Lempengan baja yang memiliki fungsi sebagai pertambahan kekakuan bantalan karet sehingga penurunan bangunan saat bertumpu diatas bantalan karet tidak terlalu besar.

Bantalan karet terbuat dari neoprene rubber yang tahan terhadap air dan suhu sehingga material ini fleksibel terhadap kondisi saat terjadi gempa bumi. Material neoprene rubber memiliki ketebalan $1 \mathrm{~mm}$ hingga $50 \mathrm{~mm}$ dengan elastisitas $25 \mathrm{~kg} / \mathrm{cm}$, pemanjangan $190 \%$, dan temperatur $-30^{\circ}$ hingga $120^{\circ} \mathrm{C}$.

Perlindungan bangunan oleh peredam mekanis ini dicapai melalui penggunaan getaran gempa bumi ke arah horizontal. Peredam mekanis memungkinkan bangunan untuk bergerak bebas saat berlangsung gempa bumi tanpa tertahan oleh pondasi, sehingga daya reaksi dapat berkurang $70 \%$ karena material karet memiliki fleksibilitas yang tinggi dan menyerap energi.

\section{KESIMPULAN}

Prinsip resilient architecture yang diterapkan pada desain Oseanarium ini adalah dengan merumuskan strategi desain yang merespon faktor eksternal dominan di Parangtritis yaitu gempa bumi, badai angin, dan tsunami.

Strategi desain resilient architecture diterapkan pada pengolahan tapak yaitu pembagian zona berdasarkan tingkat kerawanan bencana, jalur evakuasi yang mengarah ke Jalan Parangtritis, peletakan titik kumpul, orientasi bangunan yang memperhatikan arah datang gelombang, dan komposisi bangunan diletakkan pada ketinggian minimum. 
Penerapan pada pengolahan bentuk dan tata massa dengan modifikasi dari bentuk dasar lingkaran. Penerapan pada tampilan bangunan menerapkan material kaca $12 \mathrm{~mm}$ dengan finishing laminated glass.

Penerapan pada sistem struktur adalah dengan menerapkan bentuk modifikasi dari bentuk dasar lingkaran pada desain denah, penggunaan peredam mekanis, dan finishing material struktur yang ringan.

\section{REFERENSI}

Ambarwulan, W., \& Wulan, T. R. (2016). BUKU DESKRIPSI PETA DESA PARANGTRITIS (I, Vol. I). Yogyakarta: Parangtritis Geomaritime Science Park.

Damayanti, N. (2015). Recreational Waterfront Harbour Di Banten Dengan Penekanan Analogi Arsitektur. Arsitektura, 13. https://doi.org/http://dx.doi.org/10.209 61/arst.v13i1.15588

De Chiara, J., \& Crosbie, M. (2007). TimeSaver Standards for Building Types (3, illustrated ed.). McGraw-Hill, 1990.

Jose Garcia, E., \& Vale, B. (2017). Unravelling Sustainability and Resilience in the Built Environment. New York: Routledge.

Karydis, M. (2011). Organizing a Public Aquarium: Objectives, Design, Operation And Missions. Global NEST Journal, 13(No 4, pp 369-384, 2011), 16.

Meikalista, A. (2016). Akuarium Biota Laut Dengan Pendekatan Arsitektur Metafora Di Taman Nasional Karimun Jawa. Arsitektura, 14. https://doi.org/http://dx.doi.org/10.209 61/arst.v14i2.9090

Mirza, F. (2015). Disaster Mitigation Approach Of Urban Green Structure Concept In Coastal Settlement. DIMENSI Journal of Architecture and Built Environment, 42(2), $51-58$. https://doi.org/https://doi.org/10.9744/ dimensi.42.2.51-58
Nursaiful, A. (2007). Akuarium Laut. Depok: Niaga Swadaya.

Sunarto, Marfai, M. A., \& Mardiatno, D. (2010). Multirisk Assessment of Disasters In Parangtritis Coastal Area. Yogyakarta: Gadjah Mada University Press.

Widjaja, T. (2015). Aquascape: pesona taman dalam akuarium. Yogyakarta: AgroMedia Pustaka. 